\title{
CVD and PVD coating process modelling by using artificial neural networks
}

\author{
Amir Mahyar Khorasani, Mohammad Reza Solymany yazdi, Mehdi Faraji, Alex Kootsookos \\ Faculty of Hi-tech and Eng., IUIM, Tehran, Iran
}

Correspondence: Amir Mahyar Khorasani. Address: Faculty of Hi-tech and Eng., IUIM, Tehran, Iran. Telephone: 980-912-467-1816. E-mail: khorasanimahyar@yahoo.com.

Received: March 8, 2012

DOI : 10.5430/air.v1n1p46

Accepted: May 31, 2012

URL:http://dx.doi.org/10.5430/air.v1n1p46

\section{Abstract}

Thin-film coating plays a prominent role on the manufacture of many industrial devices. Coating can increase material performance due to the deposition process. Having adequate and precise model that can predict the hardness of PVD and CVD processes is so helpful for manufacturers and engineers to choose suitable parameters in order to obtain the best hardness and decreasing cost and time of industrial productions. This paper proposes the estimation of hardness of titanium thin-film layers as protective industrial tools by using multi-layer perceptron (MLP) neural network. Based on the experimental data that was obtained during the process of chemical vapor deposition (CVD) and physical vapor deposition (PVD), the modeling of the coating variables for predicting hardness of titanium thin-film layers, is performed. Then, the obtained results are experimentally verified and very accurate outcomes had been attained.

\section{Key words}

Titanium coating process, Hardness modeling, Multi-Layer perceptron, Artificial neural networks

\section{Introduction}

CVD/PVD coating or ion-injection processes have become one of the most important and significant key-technologies to protect the surface of mechanical or electric devices against various wear mechanisms and to prolong the life-time. Titanium or some ceramic materials due to their significant hardness are the typical tool materials to be used as thin layer for die materials in the metal forming ${ }^{[1-4]}$.

Various methods for the prediction of maximum hardness of titanium thin film layers have been proposed. They were not universally successful due to the complex spontaneous of the coating processes. However, the applied indirect methods suffered from the fact that not only the coated but other process parameters also influence the measurement results ${ }^{[5-11]}$.

Tadahiro et al. ${ }^{[12]}$ have investigated on iPVD Cu process integrated with iPVD Ti and CVD Cu and they used high temperature iPVD to control the thickness of deposition process. Photo catalytic measurements of titanium dioxide films deposited with metal organic decomposition have been used by Marko et al. ${ }^{[13]}$. Also, ellipsometry and finite element method has been introduced as a precise technique for measuring thin film properties by some researchers ${ }^{[14-16]}$. Furthermore, ultrasonic nondestructive testing has been presented as a useful method for characterization of microstructures, assessment of defects, and evaluation of material properties ${ }^{[17-19]}$. In recent years, Wincheski ${ }^{[20]}$ used 
eddy current impedance plane instrument with custom wound eddy current sensors to measure the thickness and hardness of material.

Although these methods are capable of measuring titanium thin-film hardness, but the major problem arises when predicting the hardness with different experiment parameters has to be characterized. So having accurate model which can estimate the hardness in PVD and CVD processes with different input parameters such as (i.e. ion bombard time, sub-layer roughness, material type, sub-layer temperature, work and chamber pressure), is vital on account of declining the time and increasing the speed of productions and subsequently, declining the total cost of the productions. In addition, by having such model CVD and PVD operators can set up coating devices for require thickness by choosing distinct coating conditions and therefore, the mentioned processes can be carried out easily and precisely. Also one of the prominent subjects for scrutinizing the industrial production lines is monitoring process and because the presence of some input factors most of the industrial processes are nonlinear solution and they can be modeled by ANNs.

In this paper, the titanium alloys such as Titanium Nitride (TIN), Titanium Carbide (TIC) and Titanium Carbide Nitride (TIC-N), by using different pressure and temperature conditions, were deposited on specimens. Then, the hardness of deposited thin layers was measured. Based on acquired experimental data, multi-layer perceptron (MLP) neural networks have been used for process modeling and predicting hardness of protective layers on various conditions. Then, the obtain results are experimentally validated.

\section{Experimentations}

To find out the hardness and corrosion of parts coated with TiC-N, TiN and TiC material a large number of specimens including two groups of circular and rectangular samples have been prepared. Using several tests based on experimental device's limitation such as pressure, rotational speed and temperature, the values of coating parameters are chosen. In a CVD process, reactant gases (often diluted in a carrier gas) at room temperature enter the reaction chamber. The substrate can be heated in resistive oven, by hot plate or by infrared lamps. So, the gas mixture is heated as it approaches the deposition surface ${ }^{[2]}$. During CVD process, the methane gas with a temperature of $700^{0}-1100^{0}$ has been injected to the layers. Voltage and coating time are selected $65 \mathrm{~V}$ and $30 \mathrm{~min}$ respectively. In all experiments, ion bombarding time and sub-layer temperature were $20 \mathrm{~min}$ and 1500 respectively.

In first group, the circular steel sub-layers with a diameter and thickness of 20 and $4 \mathrm{~mm}$ respectively (see Figure 1), have been used. Using CVD method in form of rotational sampling is applied. Specimens have been deposited by using methane gas for $\mathrm{TiC}$ layers, nitrogen gas for TiN layers, and titanium tetra chlorine gas for TiC-N layers. The schematic diagram of CVD coating process is illustrated in Figure 2.

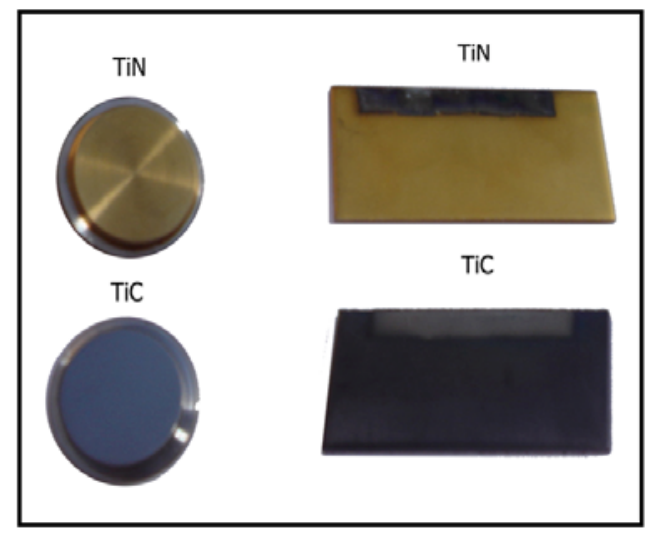

Figure 1. (Right)PVD coating samples, (Left) CVD coating samples 


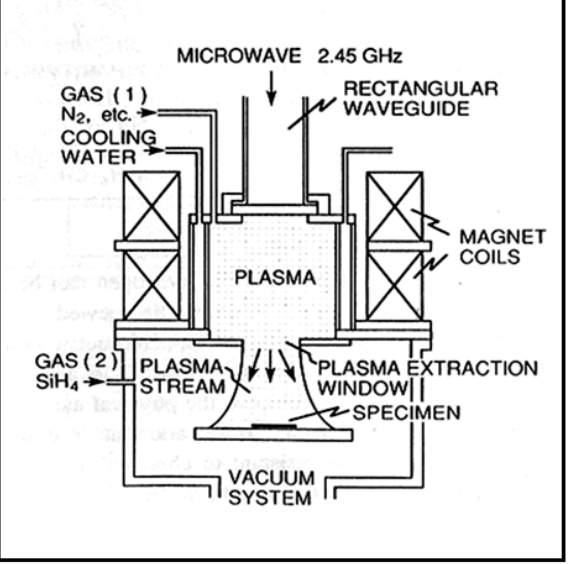

Figure 2. Schematic of CVD coating process

In second group, the rectangular steel sub-layers with two different dimensions of $75 \times 25 \times 2 \mathrm{~mm}$ and $50 \times 25 \times 2 \mathrm{~mm}$ were used.

PVD coating process can be divided into three stages: evaporation, transportation and condensation. In this approach coating material in the temperature of $800^{\circ}-1200^{\circ}$ and 65 volt in plasma circumstance were evaporated. These substances have been bombarded and condensed on work piece. Workpiece was put on rotational holder with 2 to 4 rounds per minute rotational speed and nitrogen and methane gas were utilized in this approach. Figure 3 schematically illustrates PVD coating approach.

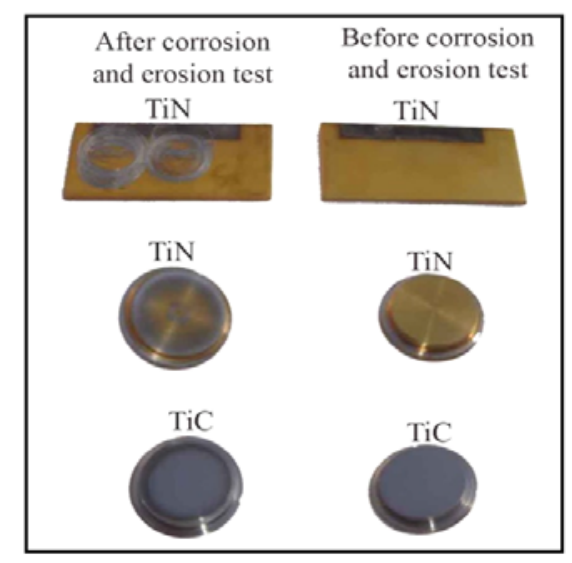

Figure 3. Coated layers before and after corrosion test

During each coating steps, a glass sub-layer under same conditions was prepared for identifying the crystalline phases and measuring thickness of the coated layers. X Ray Diffraction (XRD) analysis using Tolanski approach was applied. For measuring thickness of the coated layers on glass sub-layers as figure 4 shows an $\mathrm{X}$ ray is used as the light source. A coherent light strikes the surface of the samples (glass sub-layer) at an incident angle of 450 that is scattered. A viewing screen in parallel with the surface normal is positioned perpendicularly to the incidence plane. The distance from the rough surface to the viewing screen is approximately $0.5 \mathrm{~m}$. A charge-coupled device CCD camera (CV-M4+CL, product of JAI) serves to capture the speckle pattern and transfers the image data through a personal computer. 
For whole specimens, the obtained thickness of layer was about 4 microns for TiN and TiC layers and 8 microns for TiC-N layers.

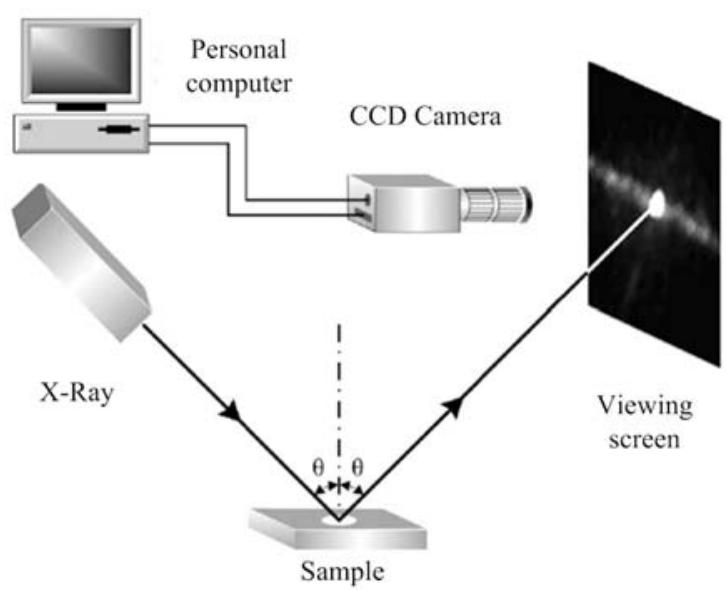

Figure 4. Thickness measurement

The hardness of 192 specimens in both groups was measured using micro hardening measurer instrument with the magnifications of 500. Furthermore, to study the influence of sub-layer roughness on hardness of thin layers, two groups of samples involving the polished and non-polished surfaces have been prepared and deposited by using TiN, TiC and TiC-N materials. The results of the maximum hardness are shown in Table 1.

Table 1. Maximum hardness of coated layers

\begin{tabular}{llll}
\hline $\begin{array}{l}\text { Hardness of the rectangular } \\
\text { sample (Vickers) }\end{array}$ & $\begin{array}{l}\text { Hardness of the circular } \\
\text { samples (Vickers) }\end{array}$ & Sub-layer roughness & Material type \\
\hline 490 & 450 & Non-polished & TiN \\
650 & 630 & Polished & \\
565 & 470 & Non-polished & TiC \\
770 & 740 & Polished & \\
810 & 790 & Non-polished & TiC-N \\
900 & 830 & Polished & \\
\hline
\end{tabular}

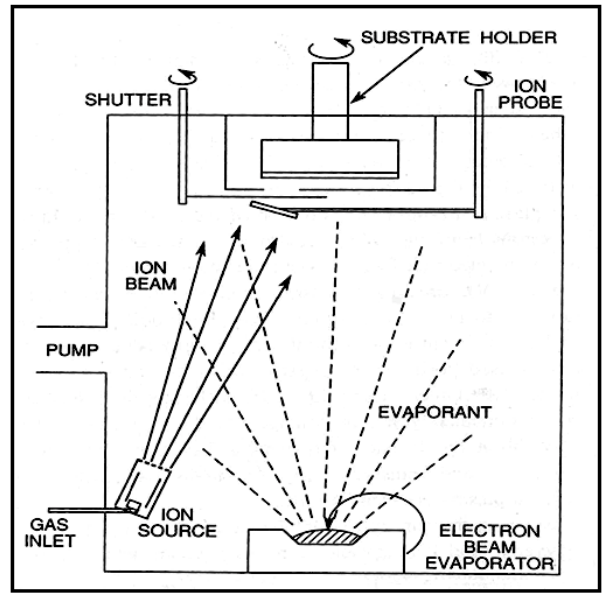

Figure 5. Schematic of PVD coating process 
Corrosion and erosion tests (i.e. high speed test) of all specimens have been carried out under various conditions (i.e. time, pressure and speed changing). For these purpose specimens were clamped to the turning machine while dynamometer was installed on tool holder. By contacting diamond tool to the samples and measuring the force and tool impact, corrosion and erosion were evaluated. Figure 5 illustrates the qualitative comparison of layers corrosion.

\section{Modeling of the titanium coating process}

Artificial neural networks (ANNs) have emerged as a well-known solution for tackling pattern recognition and classification tasks ${ }^{[22-24]}$.

In this section, based on the experimental data, the coating process modeling for hardness of titanium thin layers is carried out by using MLP neural networks that is one of the most popular supervised ANNs which have the ability to solve nonlinear problems.

156 exemplars have been used for the off-line training and design best fitted architecture.

As shown in Figure 6, a three-layers MLP is used, including 6 inputs (i.e. ion bombard time, sub-layer roughness, material type, sub-layer temperature, work and chamber pressure), 2 hidden layers containing 12 neurons, and an output layer with a single neuron (i.e. hardness of thin layer), $6 \times 6 \times 6 \times 1$. Hidden layers must have equitable covering rate on learning data. Therefore, the best architecture and parameters of the MLP model are chosen through several tests which are not presented in this paper and Hyperbolic Secant transfer functions have been utilized for neurons of hidden and output layers.

The processes that a neuron performs in this network are: multiplication of each of the inputs by its respective weight, adding up the resulting numbers for all the inputs and determination of the output according to the result of this summation and an activation function. While a single neuron is of very limited use, a number of connected neurons, i.e. a network, can be trained to perform certain tasks. Data is fed into the network through an input layer, it is processed through one or more intermediate hidden layers and finally it is fed out of the network through an output layer. The proposed network allow data to flow forward, this aspect of the network will affect its performance and the applications for which it is suited. This type of network is trained with the back propagation learning algorithm.

For the best obtained network root mean squared (RMS) error and correlation between the predictions of ANNs and experimental data for training were 0.034999 and $98.24 \%$, respectively (cf. Figures 7 and 8).

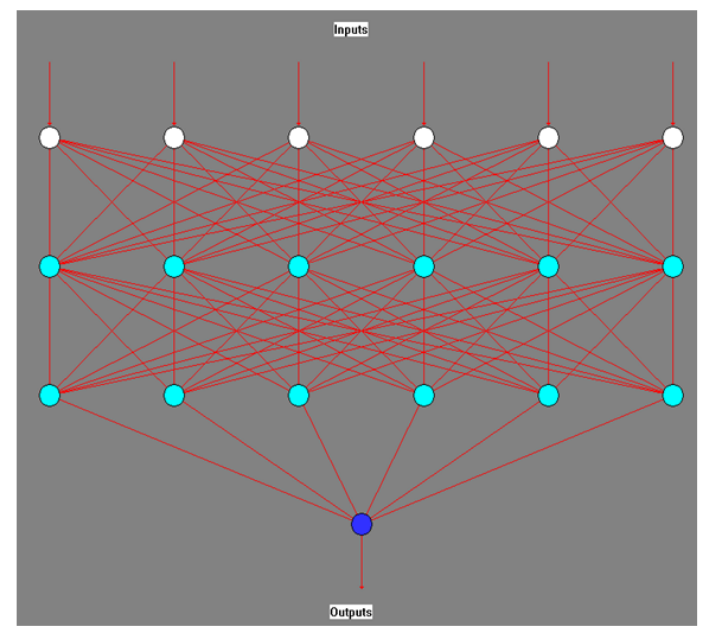

Figure 6. Proposed perceptron neural networks 


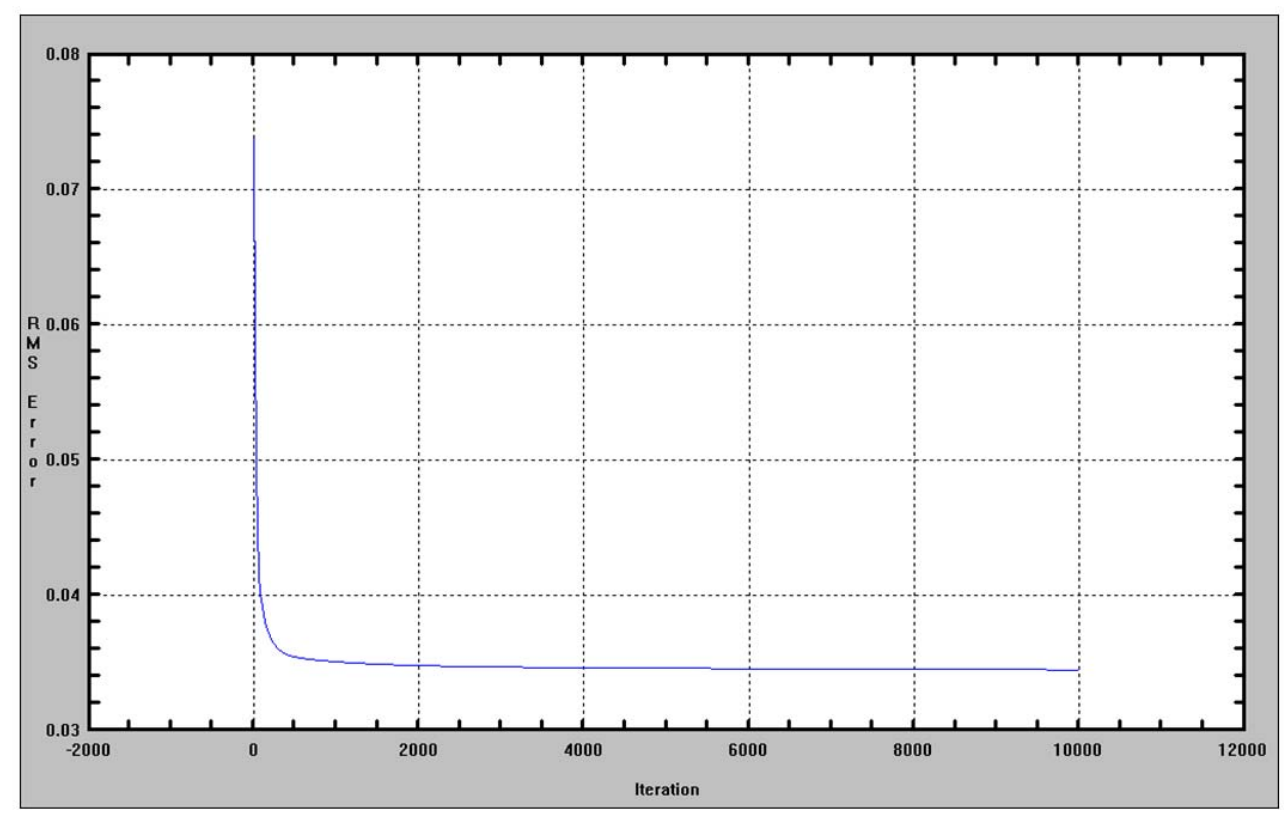

Figure 7. RMS error for training

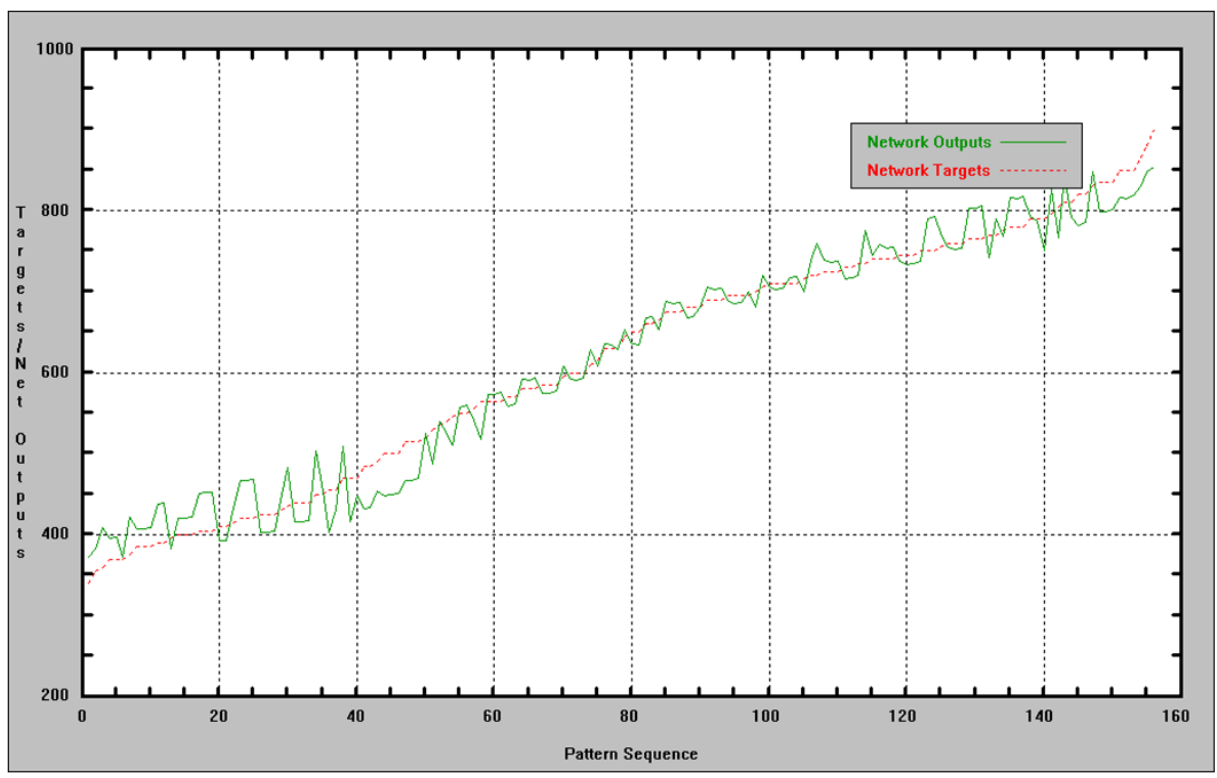

Figure 8. Correlation and curve fitting analyses for training

\section{Experimental validation of designed network}

Some experiments were conducted for testing the performance of the model. Table 2 and figure 8 show the results of the simulation and experimental measurements to determine the performance of fitted neural network. It is seen that in most cases, negligible error had been observed. 
Table 2. Experimental validation results

\begin{tabular}{|c|c|c|c|c|c|c|c|}
\hline Repetition & $\begin{array}{l}\text { Measurement } \\
\text { Hardness } \\
\text { (Vickers) }\end{array}$ & $\begin{array}{l}\text { Predicted } \\
\text { Hardness } \\
\text { (Vickers) }\end{array}$ & Error (\%) & Repetition & $\begin{array}{l}\text { Measurement } \\
\text { Hardness } \\
\text { (Vickers) }\end{array}$ & $\begin{array}{l}\text { Predicted } \\
\text { Hardness } \\
\text { (Vickers) }\end{array}$ & Error (\%) \\
\hline 1 & 355 & 380.874 & -7.2 & 19 & 645 & 652.636 & -1.1 \\
\hline 2 & 370 & 389.572 & -5.2 & 20 & 660 & 662.108 & -0.3 \\
\hline 3 & 375 & 428.637 & -14.3 & 21 & 665 & 652.636 & 1.8 \\
\hline 4 & 390 & 437.966 & -12.2 & 22 & 680 & 662.108 & 2.6 \\
\hline 5 & 395 & 380.874 & 3.5 & 23 & 695 & 705.684 & -1.5 \\
\hline 6 & 410 & 389.572 & 4.9 & 24 & 705 & 719.61 & -2 \\
\hline 7 & 415 & 442.142 & -6.5 & 25 & 710 & 714.97 & -0.7 \\
\hline 8 & 435 & 492.408 & -13.1 & 26 & 715 & 705.684 & 1.3 \\
\hline 9 & 455 & 442.142 & 2.8 & 27 & 730 & 714.97 & 2 \\
\hline 10 & 470 & 428.637 & 8.8 & 28 & 735 & 719.61 & 2 \\
\hline 11 & 485 & 437.966 & 9.6 & 29 & 735 & 776.263 & -5.6 \\
\hline 12 & 530 & 492.408 & 7 & 30 & 750 & 794.652 & -5.9 \\
\hline 13 & 535 & 543.832 & -1.6 & 31 & 755 & 775.75 & -2.7 \\
\hline 14 & 550 & 556.658 & -1.2 & 32 & 775 & 775.75 & -0.09 \\
\hline 15 & 555 & 543.832 & 2 & 33 & 795 & 843.41 & -6 \\
\hline 16 & 570 & 556.658 & 2.3 & 34 & 805 & 776.263 & 3.5 \\
\hline 17 & 595 & 603.686 & -1.4 & 35 & 820 & 794.652 & 3 \\
\hline 18 & 615 & 603.686 & 1.8 & 36 & 865 & 843.41 & 2.4 \\
\hline
\end{tabular}

As shown in Figure 9, the proposed MLP neural network has provided proper modeling results. Indeed, this method can be reliably and successfully used for modeling of the titanium coating process with $98.3 \%$ correlation.

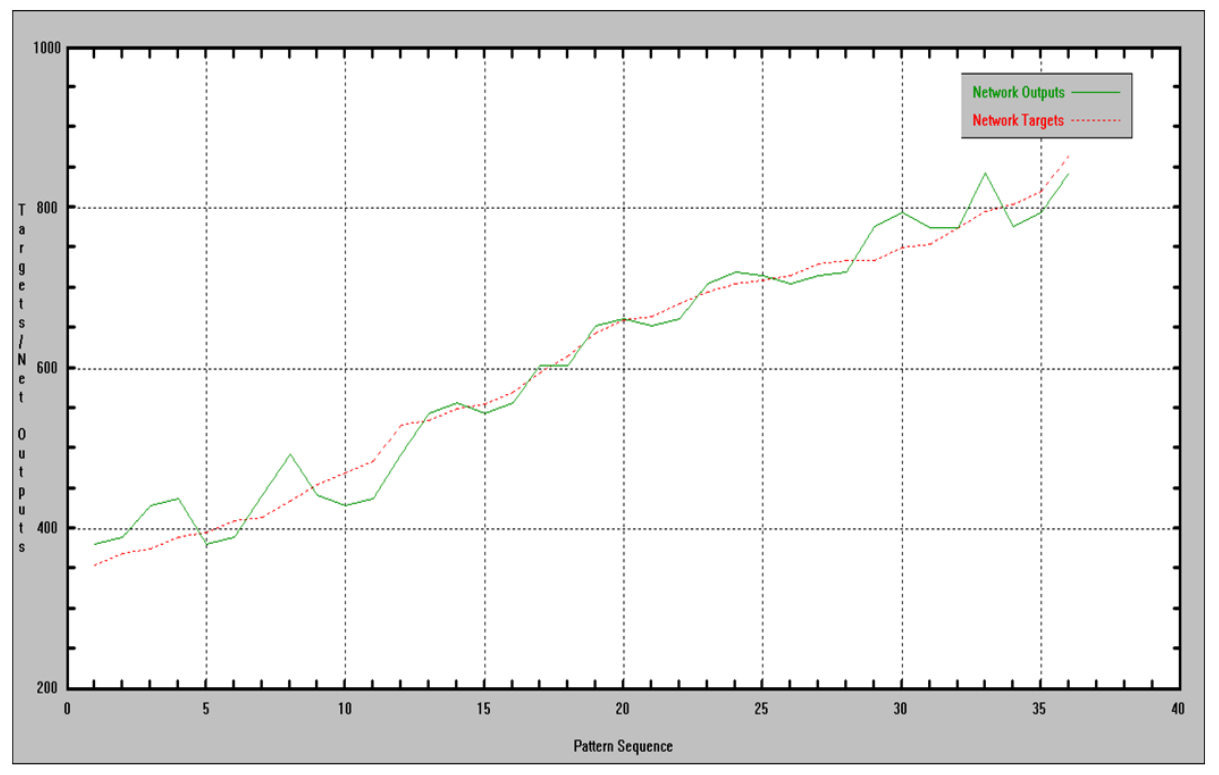

Figure 9. Correlation and curve fitting analyses for test data 


\section{Conclusions}

The present work is concerned with exploring the possibility of predicting and modeling the hardness of TiC-N, TiN and TiC on PVD and CVD coating process. Then the obtained results have been experimentally validated and it is found that ANNs can be used to find out the effective estimates and modeling of the hardness in coating process.

Having all above discussions these conclusions can be drawn that:

Coating can increase material performance due to the deposition process and increasing surface hardness.

By using MLP neural network the hardness of TiC-N, TiN and TiC on PVD and CVD coating process can be estimated precisely.

Having predictive model which can estimate the hardness of coated layers in CVD and PVD process can increase the material resistance against corrosion and erosion.

The proposed model has special ability to increases the performance and industrial cutting tool life in real manufacturing process.

The predicted results are in a proper agreement with the experimental data which illustrates the capability of the proposed neural models with the hardness of coated layers that has $98.3 \%$ accuracy.

The training finished on 30 min whereas experimental study had continued day after day so clearly ANNs is economical and saves time.

ANNs can produce an accurate relationship between coating process input and hardness. Therefore, ANNs can be used for modeling the hardness in the PVD and CVD coating process so that it can be estimated close to real values.

To conclude, this study has been involved with the ANNs operations for the model development to predict the values of the performance measurements, focusing on hardening in the coating operations.

\section{References}

[1] Dobrza'nski, and L.A., Pakuła, D. 'Comparison of the structure and properties of the PVD and CVD coatings deposited on nitride tool ceramics. 'Journal of Materials Processing Technology. 2005; 164-165: 832-842. http://dx.doi.org/10.1016/j.jmatprotec.2005.02.094

[2] Prengel, H.G., Jindal, P.C., and Wendt, K.H. 'A new class of high performance PVD coatings for cutting tools.' Journal of Surface and Coatings Technology. 2001; 139: 25-41. http://dx.doi.org/10.1016/S0257-8972(00)01080-X

[3] Ranea, C. 'Wear resistance of thin coatings based on titanium.' International Conference on Tribology, Kayseri. 15-18 July 2002; 783-788.

[4] Polini, R. et.al. 'Effects of Ti- and Zr-based interlayer coatings on hot-filament chemical vapor deposition of diamond on high-speed steel. 'Journal of Materials Engineering and Performance. 2006; 15 (2): 201-207. http://dx.doi.org/10.1361/105994906X95887

[5] Aghaie-Khafri, M., and Fazlalipour, F. 'Vanadium carbide coatings on die steel deposited by the thermo-reactive diffusion technique. 'Journal of Physics and Chemistry of Solids. 2008; 69: 2465-2470. http://dx.doi.org/10.1016/j.jpcs.2008.04.040

[6] Shtansky, D. V., et.al. 'Computational model for predicting coating thickness in electron beam physical vapor deposition.' International Journal of Manufacturing processes Synthesis and Processing. 2005; 7(2): 140-153.

[7] Singh, K., et.al. 'Magnetron Sputtered TiN Coatings Modified by Chromium, Nickel and Electro less Nickel (EN) Inter layers on Mild Steel. 'Mineral processing and extractive metallurgy Review. 2001; 22(2): 651-679.

http://dx.doi.org/10.1080/08827509808962520 
[8] Assis, S., and Costa, L. I. 'Electrochemical evaluation of Ti-13Nb-13Zr, Ti-6Al-4V and Ti-6Al-7Nb alloys for biomedical application by long-term immersion tests.' journal of Materials and Corrosion. 2007; 58(5): 329-333.

[9] Emilena, M.C., et.al. 'Evaluation of surface characteristics of Ti-6Al-4V and Tilite alloys used for implant abutments'. Journal of Braz Oral Res. 2006; 20(4): 307-311.

[10] Bull, S.J., Bhat, D.G., and Staia, M.H. 'Properties and performance of commercial TiCN coatings. Part 1: coating architecture and hardness modeling.' Surface and Coatings Technology. 2003; 163-164: 499-506. http://dx.doi.org/10.1016/S0257-8972 (02)00650-3

[11] Mathur, S., and Kuhn, P. 'CVD of titanium oxide coatings: Comparative evaluation of thermal and plasma assisted processes.' Surface\& Coatings Technology. 2006; 201: 807-814. http://dx.doi.org/10.1016/j.surfcoat.2005.12.039

[12] Ishizaka, T., et.al. 'Bottom up deposition of advanced iPVD Cu process integrated with iPVD Ti and CVD Cu.' Microelectronic Engineering. 2011; 4: 48-51.

[13] Bielawski, M., and Beres, W. 'FE modeling of surface stresses in erosion-resistant coatings under single particle impact.' Wear. 2007; 262: 167-175. http://dx.doi.org/10.1016/j.wear.2006.04.009

[14] Kone, F., and et.al. 'Finite element modeling of the thermo-mechanical behavior of coatings under extreme contact loading in dry machining. 'Surface\& Coatings Technology. 2011; 205: 3559-3566.

[15] Roth, J.A. 'Closed-loop control of resonant tunneling diode barrier thickness using in situ spectroscopic ellipsometry.' Journal of Vacuum. Science. 2000; 18: 1439. http://dx.doi.org/10.1016/j.surfcoat.2010.12.024

[16] Morton, D. E., etal. 'Optical monitoring of thin-films using spectroscopic ellipsometry.' 45th Annual Technical Conference Proceedings. 2002; 2-5.

[17] Buitrago, B., Irausquín, I., and Mendoza, J. 'Ultrasonic Evaluation of a Beta-C Titanium Alloy.' 4th International Conference on NDT. October 2007; 11-14.

[18] Kumar, A., et.al. 'Comprehensive micro structural characterization in modified 9Cr-1Mo ferritic steel by ultrasonic measurements.' Metallurgical and Materials Transactions A. 2002; 33A: 1617-1626.

[19] Kumar, A., et.al. 'Characterization of solutionizing behavior in VT14 titanium alloy using ultrasonic velocity and attenuation measurements. 'Materials Science and engineering. 2003; 360: 58-64. http://dx.doi.org/10.1016/S0921-5093(03)00495-7

[20] Wincheski, B. 'Eddy current COPV overwrap and liner thickness system and data analysis for 40-Inch Kevlar COPVs SN002 and SN027, Langley Research Center, Hampton, Virginia. 'Technical report of The NASA STI Program Office. January 2008; 2-5.

[21] Bouteville, A. 'Numerical simulation applied to chemical vapor deposition Process Rapid Thermal CVD and Spray CVD.' Journal of Optoelectronics and Advanced Materials. 2005; 7(2): 599-606.

[22] Koutroumbas, K. 'Pattern Recognition: A statistical approach. 'Academic Press. 2008; 200-210.

[23] Zain, A. M., Haron, H., Sharif, S. 'Prediction of surface roughness in the end milling machining using Artificial Neural Network. 'Expert Systems with Applications. 2010; 37: 1755-1768. http://dx.doi.org/10.1016/j.eswa.2009.07.033

[24] Karayel, D. 'Prediction and control of surface roughness in CNC lathe using artificial neural network.' journal of materials processing technology. 2009; 209: 3125-3137. 